\title{
Competitividad entre joyerías y tiendas de bisutería fina legalmente constituidas, $2013^{1}$
}

\author{
Arlen Sofía Rugama Díaz ${ }^{2}$ \\ Dania Hernández Aguilar ${ }^{3}$ \\ Jessica del socorro Laguna Blandón ${ }^{4}$ \\ Beverly Castillo Herrera ${ }^{5}$
}

1 Este artículo se basa en la investigación titulada Competitividad entre Joyerías y tiendas de bisutería fina legalmente constituidas, en el distrito I de la ciudad de Estelí, 2013. para optar al título de Administración de Empresas en el año 2012 por la UNAN-Managua, FAREM-Estelí.

2 UNAN-Managua, FAREM-Estelí. Correo electrónico: arlen.rugama@yahoo.es.

3 UNAN-Managua, FAREM-Estelí. Correo electrónico: hdania47@yahoo.es.

4 UNAN-Managua, FAREM-Estelí. Correo electrónico: lunajessi2010@hotmail.com.

5 Maestría en Ciencias Sociales por la Universidad de Guadalajara, estudiante de doctorado en Ciencias Sociales por la Universidad del Zulia. Docente titular de la UNAN-Managua, FAREM-Estelí. Correo Electrónico: beverly. castillo@yahoo.com.

\section{RESUMEN}

Esta investigación analiza las acciones de competitividad implementadas por las joyerías y tiendas de bisutería fina durante el 2013, para proponer estrategias que mejoren la capacidad competitiva de ambos negocios. La hipótesis tiene como variable independiente, proceso administrativo y como variable dependiente, competitividad.

Esta investigación es aplicada y cuantitativa; su universo de estudio son 17 joyerías y 19 tiendas de bisutería fina, para la obtención de la muestra se utilizó el muestreo probabilístico aleatorio simple, obteniendo 15 joyerías y 17 tiendas de bisutería fina. Se aplicaron encuestas y entrevistas semi estructuradas a propietarios de los negocios a fin de obtener información para soportar los resultados obtenidos en el desarrollo de esta investigación, se reforzó con investigación documental para tener un soporte teórico-conceptual, en el cual se identificaron tres ejes teóricos: Mercado, MIPYME y Competitividad.

Se evaluaron características administrativas (administración, personal y rentabilidad), mercadológicas (ubicación, clientes, venta y publicidad), ventajas y desventajas de los negocios, obteniendo como resultado que las joyerías aplican en mayor porcentaje el proceso administrativo que las tiendas de bisutería fina y por lo tanto son más competitivas.

A ambos negocios se brindan recomendaciones para mejorar su capacidad competitiva en el mercado.

Palabras clave: Competitividad, Joyerías, Bisutería, Estelí. 


\title{
Competitive between jewelry stores and fashion jewelry stores legally established, 2013 1
}

\author{
Arlen Sofía Rugama Díaz \\ Dania Hernández Aguilar ${ }^{3}$ \\ Jessica del socorro Laguna Blandón ${ }^{4}$ \\ Beverly Castillo Herrera ${ }^{5}$
}

1 This article is based on the research titled Competitive between jewelry stores and fashion jewelry stores legally established, 2013. To obtain the title of Bachelor of Business Administration from the UNAN-Managua, FAREM-Estelí.

2 UNAN-Managua, FAREM-Estelí. E-mail: arlen.rugama@yahoo.es.

3 UNAN-Managua, FAREM-Estelí. E-mail: hdania47@yahoo.es.

4 UNAN-Managua, FAREM-Estelí. E-mail: lunajessi2010@hotmail.com.

5 Master in Social Sciences from the University of Guadalajara, a PhD student in Social Sciences from the University of Zulia. Teaching holder of UNAN-Managua, FAREM-Estelí. E-mail: beverly.castillo@yahoo.com.

\begin{abstract}
This research analyzes the actions implemented by the competitive jewelry and fashion jewelry stores during 2013, to propose strategies to improve the competitiveness of both businesses. The hypothesis is as an independent variable, and administrative process as the dependent variable, competitiveness.

This research is implemented and quantitative; its universe of study include 17 and 19 jewelry stores fine jewelry, to obtain the sample simple random probability sampling was used, obtaining 15 and 17 jewelry stores fashion jewelry. Surveys and semi-structured interviews for business owners to obtain information to support the results obtained in the development of this research were applied, it was reinforced with documentary research to have a theoretical and conceptual support, in which three theoretical axes were identified: Market, MSME and Competitiveness.

Administrative features (administration, staff and profitability), market related (location, customers, sales and advertising), advantages and disadvantages of business were evaluated, resulting to the jewelry stores apply higher percentage on the administrative process that fashion jewelry stores, therefore they are more competitive.
\end{abstract}

Some recommendations were provide to both enterprises in order to help them to improve their competitive capacity in the market.

Keywords: Competitiveness, Jewelry, Fashion Jewelry, Estelí. 


\section{INTRODUCCIÓN}

Las Micro, pequeñas y medianas empresas, (MIPYME), en Nicaragua representan el $99.5 \%$ del universo empresarial, existen 154,600 negocios de ese tipo que aportan entre el $40 \%$ y el $45 \%$ del Producto Interno Bruto, (PIB), pero todavía sufren por la falta de financiamiento, tecnificación y organización, pero aun así han venido sosteniendo un crecimiento de aproximadamente $5 \%$ anual y aportando entre un $75 \%$ y $85 \%$ de los empleos.

La competitividad es importante para las MIPYMES por que les permite desarrollarse y posicionarse en una parte del mercado, sostenerse a lo largo del tiempo y crecer continuamente para responder eficazmente a los desafíos (internos y externos).

El principal problema al que se enfrentan las joyerías es la competencia por parte de las tiendas de bisutería fina ya que ofrecen productos con precios bajos y variedad de diseños y colores, a la vez estas tiendas se enfrentan a la competencia de las joyerías debido a que sus productos son calidad y duraderos.

La mayoría de las joyerías del distrito I de la ciudad de Estelí no cuentan con un sistema contable, lo que no les permite llevar un control de los ingresos y egresos de sus operaciones. Pero aun así, las exigencias del mercado han provocado en las joyerías la diversificación de productos y servicios, y se ven obligadas a ser más competitivas.

En las tiendas de ropa y calzado se comercializa bisutería fina, debido a que es un punto estratégico ya que al adquirir el vestuario se complementa con este tipo de productos. La bisutería fina se ajusta a cada temporada debido a su variedad de diseños y colores y se oferta principalmente a las mujeres ya que son el principal consumidor de este tipo de productos.
El propósito de esta investigación es facilitar información y enriquecer los conocimientos de las joyerías y tiendas de bisutería fina para aplicar acciones competitivas acertadamente en el mercado, además permitirá a la universidad (FAREM-Estelí) tener un documento que servirá como antecedente y apoyo a futuros estudiantes que deseen conocer o ampliar más acerca de MIPYME y competitividad, también la Alcaldía Municipal de Estelí y distintos organismos podrán aprovechar este documento como guía para fomentar la competitividad entre las MYPIMES y crear conciencia entre estos empresarios para hacer buen uso de estrategias para el crecimiento de su negocio.

Como objetivo principal se planteó, Analizar las acciones de competitividad que implementan las joyerías y tiendas de bisutería fina para la propuesta de estrategias que mejoren la competitividad de las joyerías y tiendas de bisutería fina, ubicadas en el distrito I de la ciudad de Estelí, 2013.

La hipótesis que guía esta investigación expresa: Una adecuada aplicación del Proceso Administrativo en las Joyerías influye en la competitividad con respecto a las tiendas de bisutería fina.

\section{MATERIALES Y MÉTODOS}

El universo de estudio son: 17 Joyerías y 19 tiendas de bisutería fina legalmente constituidas ubicadas en el distrito I de la ciudad de Estelí. Con la realización de los cálculos correspondientes y teniendo un margen de error del $5 \%$ y un nivel de confianza del $95 \%$, el tamaño de la muestra fue de 15 joyerías y 17 tiendas de bisutería fina pero para la obtención de mayor información se decidió tomar el total del universo con el fin de obtener mejores resultados.

Para la realización de esta investigación se determinó que el tipo de muestreo a utilizar es el muestreo probabilístico aleatorio simple. Para ello se solicitó a la alcaldía la lista de las joyerías y tiendas de bisutería 
fina legalmente inscritas en el distrito I de la ciudad de Estelí y con dicha lista se visitó cada establecimiento a fin de verificar la existencia de cada negocio, además se incluyeron negocios que la alcaldía municipal no tenía registrados para realizar el estudio.

Esta investigación es aplicada por que se enfoca en el estudio de la competitividad entre las joyerías y tiendas de bisutería fina ubicadas en el distrito I de la ciudad de Estelí, se analiza este aspecto del mercado y se proponen soluciones que permitan alcanzar una adecuada aplicación del proceso administrativo y es una investigación cuantitativa porque se define la relación entre las variables proceso administrativo y competitividad de los negocios donde se utilizan técnicas de recolección de datos para obtener información sólida que permita probar la hipótesis.

Las técnicas de recolección de datos utilizadas fueron: encuestas y entrevistas semi estructuradas dirigidas a propietarios de joyerías y tiendas de bisutería fina, ya que son los informantes claves para el desarrollo de esta investigación, proporcionan información valiosa que servirá de parámetro para identificar las características competitivas tanto administrativas como mercadológicas y por lo tanto sus principales ventajas y desventajas.

\section{RESULTADOS Y DISCUSIÓN}

\section{Los ejes teóricos de la investigación}

Para tener un soporte teórico, se elaboró el marco teórico-conceptual de investigación en base a: mercado, MIPYMES y competitividad.

Según Mantilla, mercado es el conjunto de compradores reales y potenciales de un producto. Estos compradores comparten una necesidad o un deseo particular que puede satisfacerse mediante una relación de intercambio. (2003, p10).
Las MIPYMES, son todas aquellas micro, pequeñas y medianas empresas, que operan como persona natural o jurídica, en los diversos sectores de la economía, siendo en general empresas manufactureras, industriales, agroindustriales, agrícolas, pecuarias, comerciales, de exportación, turísticas, artesanales y de servicio, entre otras. (Asamblea Nacional de la Republica de Nicaragua, 2008).

La competitividad es la capacidad que tiene una organización de mantener sistemáticamente ventajas competitivas que le permitan alcanzar, sostener y mejorar una determinada posición en el mercado. Más aún, se puede decir que es hacer las cosas mejor que los demás. De esta manera, la competitividad está directamente relacionada con la forma de planear y desarrollar cualquier iniciativa de negocios. Cuando el empresario se toma el tiempo necesario para planear, esto es, establecer metas y objetivos, diseñar programas para alcanzarlos y realizar la evaluación para mantener al día los planes, en fin, para tener el control, está identificando las oportunidades que le permiten ser proactivo y ser más competitivo. (Briones, 2010).

Principales características administrativas (administración, personal, rentabilidad) de las joyerías y tiendas de bisutería fina.

\begin{tabular}{|l|r|r|l|l|}
\hline Tiempo de Operar & Joyerías & $\%$ & $\begin{array}{l}\text { Tiendas de } \\
\text { Bisutería Fina }\end{array}$ & \multicolumn{2}{l|}{$\begin{array}{l}\text { J } \\
\text { 0 a 5 años }\end{array} \quad 4$} & 24 & 14 & 74 \\
\hline 6 a 10 años & 3 & 18 & 5 & 26 \\
\hline 11 a 15 años & 4 & 24 & 0 & 0 \\
\hline De 16 años a mas & 6 & 34 & 0 & 0 \\
\hline Total & 17 & 100 & 19 & 100 \\
\hline
\end{tabular}

Cuadro $\mathrm{N}^{\circ} 1$. Tiempo de Operar el Negocio Universo. 17 Joyerías y 19 Tiendas de Bisutería Fina

Fuente. Datos primarios de encuesta, Mayo 2013.

El $34 \%$ de las joyerías tienen más de 16 años de funcionar, son negocios que están posicionados fuertemente en el mercado. En cambio, el $74 \%$ de 
las tiendas de bisutería fina son negocios que están incursionando en el mercado en los últimos 5 años.

Generalmente la inversión inicial y los gastos operativos de las joyerías y tiendas de bisutería fina provienen de los ahorros, préstamos o aporte familiar

Opinión de un Joyero. "mi negocio tiene 17 años de funcionar debido a la estabilidad que me ha brindado el mercado y también que los productos que ofrezco son de alta calidad y por lo tanto la gente que conoce este establecimiento sabe que mis productos son confiables".

\begin{tabular}{|l|r|r|l|l|}
\hline Planeación & Joyerías & \multicolumn{2}{l|}{$\begin{array}{l}\text { Tiendas de } \\
\text { Bisutería Fina }\end{array}$} & \multicolumn{2}{l|}{\begin{tabular}{l} 
J \\
\hline $\mathrm{Si}$
\end{tabular}$\quad 12$} & 71 & 9 & 47 \\
\hline No & 5 & 29 & 10 & 53 \\
\hline Total & 17 & 100 & 19 & 100 \\
\hline
\end{tabular}

Cuadro $\mathbf{N}^{\circ}$ 2. Planificación de Actividades

Universo. 17 Joyerías y 19 Tiendas de Bisutería Fina

Fuente. Datos primarios de encuesta, Mayo 2013.

En las joyerías principalmente es el dueño el que administra el negocio ya que prefieren ser ellos quienes toman las decisiones de su negocio y así decidir qué es lo mejor en cambio en las tiendas de bisutería fina la mayoría tienen un encargado de la tienda que es el mismo que lleva el control del negocio.

El $71 \%$ de las joyerías y solamente el $47 \%$ de las tiendas de bisutería fina planifican sus actividades ya que es un elemento muy importante para llevar la administración del negocio, además realizan evaluaciones para identificar el funcionamiento del negocio, identificar posibles problemas o desviaciones, también llevan contabilidad porque es un medio muy importante para verificar tanto los gastos como las ventas realizadas y así mismo identificar las pérdidas o utilidades del negocio la cual se lleva principalmente en libros contables como manifestó el 59\% de los propietarios de las joyerías y en menor porcentaje el $47 \%$ de las tiendas de bisutería fina.
Opinión de un Joyero "para mi es importante realizar las evaluaciones correspondientes para ver si realmente está funcionando como debe ser y así ver si hacen falta productos, en que tiempo se vende más ya que si no realizáramos evaluaciones al negocio estaríamos como en un precipicio donde en cualquier momento mi negocio se puede ir al abismo"

La mayoría de los propietarios de las joyerías tienen planes de ampliar sus instalaciones, así como posicionarse en el mercado como fuerte competidor y por lo tanto sus ganancias son destinadas a la reinversión ya que esto les permite dar movimiento a su dinero y así mismo mantener el negocio en el mercado, en cambio solamente algunos de los propietarios de las tiendas de bisutería fina afirman que desean ampliar sus instalaciones pero su interés principal es permanecer en el mercado o tener un medio para sustentar su hogar.

Las joyerías son fuentes generadoras de empleos ya que contratan de 2 a 5 trabajadores principalmente familiares y contratación fija, en cambio en las tiendas de bisutería contratan únicamente un trabajador y esta persona por lo general es un particular. En ambos negocios no consideran importante brindar capacitación a su personal ya que solo al momento de iniciar labores en los negocios los capacitan y las cuales consisten en enseñarles cómo se hacen las joyas en el caso de las joyerías y en el caso de las tiendas de bisutería fina se les capacita para atender bien al cliente.

Las joyerías y en menor proporción las tiendas de bisutería fina utilizan el almuerzo y el aumento del salario como estrategias de motivación al personal ya que así obtienen mayores beneficios.

Como expresa un Joyero. "yo prefiero brindar el almuerzo a mis trabajadores ya que me sale más rentable que perder una hora de trabajo y así mato dos pájaros de un solo tiro ellos están satisfechos en 
no tener que moverse para ir hasta sus hogares y así logro que ellos no pierdan de trabajar."

Las joyerías consideran la rentabilidad de sus negocios muy buena ya que el margen de ganancias diarias en sus negocios es de 1001-1500 córdobas en temporadas bajas y las medidas utilizadas para incrementar su rentabilidad son reducción del precio de venta, análisis de competidores, motivación de trabajadores, en cambio las tiendas de bisutería fina consideran su rentabilidad regular ya que sus ganancias oscilan entre 501-1000 córdobas diarios y utilizan la reducción del precio de venta y motivación de trabajadores como medidas para incrementar su rentabilidad.

En las tiendas de bisutería fina se vende siempre pero lo que hace que las joyerías tengan más ganancias es debido a su calidad y el alto costo de las joyas.

Principales características mercadológicas (ubicación, clientes, venta, publicidad) de las joyerías y tiendas de bisutería fina

\begin{tabular}{|l|r|r|l|r|}
\hline $\begin{array}{l}\text { Tiempo de } \\
\text { Ubicación }\end{array}$ & Joyerías & \multicolumn{1}{l|}{$\begin{array}{l}\text { Tiendas de } \\
\text { Bisutería Fina }\end{array}$} & \multicolumn{2}{l|}{$\%$} \\
\hline Menos de un año & 2 & 12 & 6 & 32 \\
\hline De 1 a 5 años & 4 & 23 & 9 & 47 \\
\hline De 6 a 10 años & 8 & 47 & 4 & 21 \\
\hline Más de 10 Años & 3 & 18 & 0 & 0 \\
\hline Total & 17 & 100 & 19 & 100 \\
\hline
\end{tabular}

Cuadro $\mathrm{N}^{\circ} 3$. Tiempo de estar instalado en el establecimiento

Universo: 17 Joyerías y 19 Tiendas Bisutería Fina

Fuente. Datos primarios de encuesta, Mayo 2013.

Un $23 \%$ de las joyerías tienen de 1 a 5 años de estar instalados sobre la avenida central los que iniciaron vendiendo sus productos desde su casa de habitación y decidieron trasladarse a este sector, ya que es un punto estratégico para maximizar las ventas debido a que hay un mayor tránsito de personas, lo que hace visible el negocio a toda la población, la mayoría de las tiendas de bisutería es decir un $47 \%$ están ubicadas desde que surgieron en la avenida central.
La ubicación de estos negocios es muy importante ya que de esto depende gran parte del éxito o fracaso del negocio, por lo que influye en atraer más clientes, que se vuelva un negocio reconocido y por ende que aumenten las ventas. Así lo expresa un entrevistado: "La ubicación de mi negocio ha sido un factor muy importante para que los productos se muevan ya que permite la afluencia de clientes debido a que es un punto estratégico donde el producto esta accesible a la población".

La mayoría de los propietarios de las joyerías y en menor proporción las tiendas de bisutería fina se preocupan por saber si el cliente está satisfecho con el producto y servicio que se les brinda, ya que de esto depende que el cliente regrese al negocio o no. Por ello es importante mantener satisfecho a sus clientes si quieren llegar a ser exitosos en el mercado por lo que utilizan el buzón de sugerencias y la observación como estrategias para determinar la satisfacción de sus clientes.

Opinión de un joyero. "a mí siempre me gusta observar a mis clientes para saber cómo reaccionan ante los productos que ofrezco y ver a cuales se inclinan más para así tener en cuenta que producto es el que más le gusta a la población".

Las estrategias utilizadas por estos negocios para mantener a sus clientes fieles son la buena atención ya que es muy importante para que el cliente se sienta cómodo y desee regresar al negocio y también se utilizan los descuentos por compras. 


\begin{tabular}{|l|r|r|r|r|}
\hline Estrategias & Joyerías & \multicolumn{1}{l|}{$\%$} & $\begin{array}{l}\text { Tiendas de } \\
\text { Bisutería Fina }\end{array}$ & \multicolumn{2}{l|}{$\%$} \\
\hline Venta directa & 17 & 100 & 19 & 100 \\
\hline Intermediarios & 2 & 12 & & 0 \\
\hline Crédito & 2 & 12 & & 0 \\
\hline $\begin{array}{l}\text { Llamadas } \\
\text { telefónicas }\end{array}$ & 4 & 24 & & 37 \\
\hline $\begin{array}{l}\text { Sistema de } \\
\text { apartado }\end{array}$ & 2 & 12 & & 0 \\
\hline $\begin{array}{l}\text { Lleva uno y el } \\
\text { otro a mitad de } \\
\text { precio }\end{array}$ & & & & \\
\hline Dos por uno & & 0 & & \\
\hline
\end{tabular}

Cuadro $\mathrm{N}^{\circ} 4$. Estrategias de venta

\section{Universo. 17 Joyerías y 19 Tiendas de Bisutería}

Fuente. Datos primarios de encuesta, Mayo 2013.

El $100 \%$ de las joyerías y las tiendas de bisutería fina utilizan como estrategia de venta la venta directa por que los propietarios de los negocios así pueden tener un mejor control del mismo y así no corren el riesgo de tener pérdidas por algún cliente quede mal, además este método no requiere trabajo de planeación y es más rápido al momento de hacer la venta.

Los propietarios de las joyerías manifestó que los periodos de mayor demanda de sus productos son las fechas festivas: los meses de febrero, mayo, el último trimestre del año por las graduaciones mientras que las tiendas de bisutería venden sus productos constantemente en todos los meses del año.

Los propietarios de las joyerías y de las tiendas de bisutería fina manifestaron que hacen uso de los diferentes medios publicitarios para dar a conocer sus negocios entre los que mencionaron: radial, pancartas, volantes y anunciándose en las revistas existentes en la ciudad de Estelí; en ambos negocios sus propietarios coincidieron que la mejor publicidad es la de individuo a individuo ya que dependiendo de la calidad del producto y de la atención que se le brinde al cliente este hablara del negocio a otras personas que se convertirán en clientes del negocio y además esta forma de dar publicidad es muy eficaz y no requiere de costo alguno.
En las joyerías sus principales clientes son tanto hombres como mujeres, mientras que las tiendas de bisutería están segmentadas para el mercado femenino; no obstante hay ocasiones en las que llegan hombres a los establecimientos de las tiendas de bisutería fina buscando nuestros productos para regalar a la mamá o la novia esto en las fechas festivas.

\section{Análisis de las principales ventajas y desventajas de las joyerías.}

\section{Ventajas}

Las joyerías son negocios que han logrado una buena posición en el mercado debido a que estos surgieron hace más de 16 años. Su estabilidad en el mercado se debe a que han logrado posicionar sus productos y el negocio como tal en la mente de los consumidores brindándoles un producto de calidad y una buena atención a los clientes; en estos negocios el cliente siempre tiene la razón.

La ubicación de las joyerías es estratégica ya que se ubican sobre la avenida central donde hay mayor afluencia de personas, se hace visible a toda la población ya que es un lugar muy transitado.

Los productos ofertados por las joyerías están segmentados para un mercado con mayor poder adquisitivo debido a que el costo de la materia prima se ha elevado en los últimos años, a esto se agrega los costos de producción que hacen que el producto final tenga un alto costo, esto conlleva a que las personas adquieran los productos como un título valor.

Las joyerías son consideradas como empresas generadoras de empleo puesto que contratan de 2 a 5 trabajadores debido a que ellos llevan un proceso productivo en el cual se involucran un mayor número de personas. 
Los productos que ofrecen las joyerías son considerados por sus clientes como productos de calidad por que los trabajos se realizan con materia prima de calidad y además se trabaja de acuerdo a las especificaciones del cliente, en estos tipos de negocios la opinión del cliente es muy importante por lo que se da al cliente lo que pide.

\section{Desventajas}

Lucir prendas de oro es un temor latente para los ciudadanos ya que siempre está presente la inseguridad debido a que el oro es un punto muy importante en la mira de los delincuentes, por tal razón prefieren recurrir a la bisutería fina donde se encuentran prendas muy bonitas y al lucirlo no se corre el riesgo de ser asaltado y se puede andar libremente sin ningún temor por la ciudad.

Únicamente utilizan la venta directa como estrategia de venta, lo cual no les permite crecer, mientras que si utilizaran a intermediarios podrían captar mayor número de clientes y así podrían llegar incluso a personas que no conocían estos negocios.

La mayor demanda en las joyerías se concentra en las fechas festivas como: octubre, noviembre y diciembre por las graduaciones y la navidad, febrero por el mes del amor y la amistad, mayo por el día de las madre; el resto de los meses la demanda es baja, debido a la situación económica que enfrenta el país y el alto costo de las prendas.

No cuentan con un sistema contable computarizado, debido a la falta de conocimientos de aplicación de este tipo de sistemas. La planificación implementada en las joyerías es deficiente, ya que lo hacen poco y a corto plazo.

\section{Análisis de las principales ventajas y desventajas de las tiendas de bisutería fina}

\section{Ventajas}

Las tiendas de bisutería fina están ubicadas en un punto estratégico ya que sobre la avenida central es donde hay mayor afluencia de personas y se hace visible a toda la población.

La bisutería fina, tiene precios accesibles y cuentan con una amplia gama de diseños y colores que se adaptan a cada temporada del año y también al gusto de cada cliente.

La bisutería fina, se vende constantemente y está ubicada en tiendas donde se vende la ropa y el calzado por lo que al adquirir el vestuario también adquieren la bisutería como un complemento ya que su objetivo al llegar a la tienda no era comprar la bisutería.

\section{Desventajas}

La mayoría de estos negocios no llevan contabilidad, sus registros los llevan en un cuaderno, esto porque no lo consideran necesario.

Son negocios que están incursionando en el mercado con menos de cinco años de haber iniciado operaciones.

La mayoría de estas tiendas de bisutería fina no aplican un proceso administrativo, lo cual les impide desarrollarse en el mercado.

\section{Líneas estratégicas que mejoren la competitividad de las joyerías y las tiendas de bisutería fina}

\section{Estrategias para las Joyerías}

Establecimiento de un plan estratégico, en la cual se elaborará un documento con la misión, visión y objetivos del negocio, se reproducirá la información del documento a los trabajadores y se desarrollará el trabajo acorde con el plan estratégico establecido. 
Implementación de los factores claves de la competitividad (estrategia y planificación, flexibilidad, investigación y desarrollo, capital humano, innovación, calidad, productividad, calidad del servicio e imagen), en la cual se preparará a los trabajadores sobre el nuevo modelo de trabajo, se remodelará el local para darle una imagen de profesionalismo y se elaboraran etiquetas personalizadas o empaque donde se incluya la información del negocio.

Determinación del internet como medio publicitario, el que se realizará con la creación de cuentas en páginas sociales de internet como Facebook o twitter para dar a conocer el negocio, se actualizará la información y se invitarán a clientes potenciales para que visiten sus páginas y así conozcan sus servicios y productos a detalle.

Establecimiento de sistemas contables computarizados, se realizará primeramente definiendo el sistema contable adecuado para el negocio en el cual se lleva un registro de las entradas y salidas de efectivo y se elaborarán los estados financieros.

Desarrollo de nuevas técnicas de venta, en esta se reclutará el personal para la venta de joyas por catálogo, se capacitará al personal y se incentivarán económicamente por el cumplimiento de metas de ventas.

\section{Estrategias para las tiendas de bisutería}

Establecimiento de sistemas contables, en la cual se definirá un sistema contable adecuado para el negocio donde se registrarán las entradas y salidas de efectivo y se elaborarán estados financieros.

Desarrollo de nuevas técnicas de venta, en la que se reclutará al personal para la venta de joyas por catálogos se capacitarán y se incentivarán económicamente por el cumplimiento de metas de ventas.
Inversión en publicidad en la que se cotizarán los medios publicitarios más accesibles y se utilizarán como medio para dar a conocer el negocio y por lo tanto se definirá un porcentaje para publicidad.

\section{CONCLUSIONES}

Al realizar el análisis de los resultados se concluyó que:

La hipótesis se cumple ya que las joyerías aplican en mayor grado el proceso administrativo que las tiendas de bisutería debido a que el $71 \%$ planifica sus actividades, factor muy importante para el desarrollo organizacional. Lleva contabilidad en libros contables y destina un porcentaje a la reinversión, en cambio solamente el $53 \%$ de las tiendas de bisutería fina planifica sus actividades pero muy superficial debido a que solo anotan cuanto fueron sus ventas, lleva contabilidad solamente en anotaciones en cuadernos y reinvierten solo para mantener el inventario.

Las joyerías aplican medidas para incrementar su rentabilidad como; motivación de trabajadores, reducción del precio de venta y sus promedios de venta diaria oscilan entre 1001 a 1500 córdobas, en temporadas bajas. En cambio en las tiendas de bisutería fina utiliza en menor proporción medidas para incrementar su rentabilidad, como reducción del precio de venta y sus promedios de venta diaria oscilan entre 501 a 1000 córdobas debido a que la bisutería es más barata que la joyería y por lo tanto aunque vendan más obtienen menos beneficios que las joyerías.

El $34 \%$ de las Joyerías tienen más de 16 años de funcionar en el mercado lo que les ha permitido ser reconocidas como negocios que ofrecen productos de calidad y duraderos, considerados como título valor, en cambio las tiendas de bisutería fina el 74\% tiene menos de 5 años, pero se posiciono fuertemente debido a que satisface los gustos de consumidores, 
ya que ofrece productos a precios más accesibles, variedad en diseños y se adaptan a cada temporada.

Las joyerías son consideradas fuentes generadoras de empleo pues un $59 \%$ contratan de dos a cinco trabajadores, en cambio en las tiendas de bisutería fina solo contratan a un trabajador que se encarga de la atención al cliente.

\section{RECOMENDACIONES}

Recomendamos a los propietarios de las joyerías, implementar las estrategias propuestas en esta investigación, entre las cuales están:

- El establecimiento de un plan estratégico del negocio para lograr el cumplimiento eficaz y eficiente de los objetivos.

- La implementación de los factores claves de la competitividad (estrategia y planificación, flexibilidad, investigación y desarrollo, capital humano, innovación, calidad, productividad, calidad del servicio e imagen) para lograr diferenciarse de la competencia.

- La determinación del internet como medio publicitario para dar a conocer los productos a un mayor número de clientes.

- El establecimiento de sistemas contables computarizados para llevar un mejor orden de las transacciones del negocio.

- Desarrollo de nuevas técnicas de venta como: intermediarios para comercializar los productos mediante ventas por catálogo.

Recomendamos a los propietarios de las tiendas de bisutería fina, implementar las estrategias propuestas en esta investigación, tales como:

- Establecimiento de sistemas contables para poder llevar un mejor control de las transacciones del negocio.

- Desarrollo de nuevas técnicas de venta como: intermediarios para comercializar los productos mediante ventas por catálogo.

- Inversión en publicidad para dar a conocer sus productos y así captar un mayor número de clientes.

Recomendamos a la Universidad FAREM-Estelí incentivar a los estudiantes a realizar más estudios sobre MIPYMES de la Ciudad de Estelí ya que son las principales fuentes de desarrollo de la economía del Municipio.

\section{BIBLIOGRAFÍA}

Kloter P, Armstrong G, Cámara D y Cruz I. (2005). Marketing. Concepto de Mercado. (10 a ed) México. McGraw-Hil Consultado el 30 de agosto de 2013. I. Pag 10.

Asamblea Nacional de la Republica de Nicaragua. (2008). Ley $N^{\circ}$ 645. Ley de promoción, fomento y desarrollo de la micro, pequeña y mediana empresa. [versión electrónica]. Consultado el 20 de abril de 2013. Disponible en: http://legislacion. asamblea.gob.ni/Normaweb.nsf/\%28\$All\%29/EC 29253DD104D7D30625741D005C6C8C?OpenD ocument

Briones, J, A. (2010). Competitividad Microempresas. [Versión electrónica]. Consultado el 21 de abril de 2013. Disponible en: http://elempresario.mx/ actualidad/competitividad-microempresas

STONER J., WANKEL C. (1990) Administración. Prentice-Hall. México. Consultado el 21 de abril de 2013. 